Research Article

\title{
Study on Pressure Relief Effect and Rock Failure Characteristics with Different Borehole Diameters
}

\author{
Shiwei Liang $\mathbb{D},{ }^{1,2}$ Long Zhang, ${ }^{3}$ Di Ge, ${ }^{2}$ and Qiong Wang ${ }^{4}{ }^{4}$ \\ ${ }^{1}$ School of Human Settlements and Civil Engineering, Xi'an Jiaotong University, Xi'an 710049, China \\ ${ }^{2}$ Xi'an Kedagaoxin University, Xi'an 710109, China \\ ${ }^{3}$ Gansu Chemical Industry Research Institute Co., Ltd., Lanzhou 730000, China \\ ${ }^{4}$ Department of Emergency Technology and Management, North China Institute of Science \& Technology, Beijing 101601, China
}

Correspondence should be addressed to Qiong Wang; wq1989@126.com

Received 6 June 2021; Accepted 29 June 2021; Published 7 July 2021

Academic Editor: Gan Feng

Copyright ( $\odot 2021$ Shiwei Liang et al. This is an open access article distributed under the Creative Commons Attribution License, which permits unrestricted use, distribution, and reproduction in any medium, provided the original work is properly cited.

\begin{abstract}
Rock burst is a common tunnel and mine dynamic disaster, especially for deep buried tunnels, which often leads to tunnel construction delay and even induces tunnel collapse and subsidence of strata. Rock drilling is one of the effective pressure relief methods to prevent these disasters. In order to study the influence of borehole diameter on rock mass pressure relief effect, indoor acoustic emission characteristics and numerical simulation of rock samples with different borehole diameter were studied. The research result shows that with the increase in borehole diameter, the effect of borehole pressure relief is better. Different borehole diameters do not change the overall trend of acoustic emission evolution, but it will lead to different acoustic emission count characteristics of rock damage and failure, especially the maximum acoustic emission count characteristics and corresponding strain values. The existence of drilling will lead to the failure stress of rock in advance. Moreover, the existence of drilling causes a great change in the failure mode of the specimen.
\end{abstract}

\section{Introduction}

Rock burst is a common tunnel and mine dynamic disaster, especially for deep buried tunnels, which often leads to tunnel construction delay and even induced tunnel collapse and subsidence of strata [1-4]. Therefore, the control and research of tunnel rock burst are hot and difficult topics. At present, the commonly used rock burst control technology of tunnel is drilling pressure relief method $[5,6]$. Drilling pressure relief technology is to form a weakening zone in the rock mass through drilling holes and provide release space for the accumulated energy so as to reduce the risk of rock burst.

Scholars from home and abroad have carried out a lot of research on the mechanism of tunnel drilling to prevent rock burst [7-20]. Krajcinovic and Silva [7] through the experimental test studied the diameter and spacing of drilling hole on the pressure relief effect, and the research result shows that the pressure relief effect is good when the hole diameter is $300 \mathrm{~mm}$ and the hole spacing is $1.5 \mathrm{~m}-2.0 \mathrm{~m}$; if the hole spacing is increased to $3 \mathrm{~m}$, the pressure relief effect is reduced. Zhai et al. [8] thought that large-diameter drilling is more suitable for large area stress relief. The research results of Jia et al. [11] showed that the stress release caused by crack propagation and penetration around the borehole is the fundamental reason for the pressure relief effect of the borehole, and the larger the diameter and depth of the borehole, the smaller the spacing between the boreholes, the better the pressure relief effect of the borehole. Yi et al. [12] used FLAC numerical simulation to analyze the pressure relief effect of large-diameter drilling in soft and hard coal seam; the research results show that the pressure relief effect of drilling in soft rock is better than that in hard rock. Ma et al. [14] found that the weakening zone formed by drilling destroyed the bearing structure of coal body, greatly reduced the stress of shallow coal body of roadway side, and destroyed the stress condition of rock burst. Gai et al. [15] evaluated the rationality of pressure relief drilling spacing 
based on the expansion and closure of plastic zone of drilling holes and found that the coupling effect of adjacent drilling holes was strengthened, and the pressure relief range and efficiency were increased with the decrease in drilling spacing. Li et al. [16] analyzed the safety parameters of the pressure relief drilling in the dangerous coal seam and found that the larger the hole diameter of the pressure relief drilling, the better the pressure relief effect. Zhao et al. [17] applied the physical model and acoustic emission technology to study the fracture evolution of rock with prefabricated circular hole and found that tensile splitting cracks occurred parallel to the loading direction, and compressive cracks occurred on both sides of the hole. Wu et al. [19] used the DIC method to monitor five kinds of prefabricated drilling samples and obtained the fracture development and stress distribution of different types of samples. Lin et al. [20] studied the crack initiation, coalescence mechanism, and failure behavior of granite samples with different pore size, distribution, and spacing. The above research analyzes the mechanism and effect of drilling pressure relief from the stress, deformation and the layout form, and characteristics of drilling, which is of great significance for engineering safety control. However, the current research rarely analyzes the influence of the change of borehole diameter on the pressure relief effect and failure characteristics of rock mass.

In this paper, based on previous studies, indoor tests and particle discrete element simulation of rocks with different borehole diameters are carried out. Firstly, the pressure relief effect of different borehole diameters on rock mass is analyzed; secondly, the acoustic emission characteristics of rock failure are analyzed; finally, the propagation and evolution process of microcracks are analyzed, and the failure mechanism of borehole sandstone is revealed. The research provides certain guidance and reference for drilling pressure relief of coal and rock mass.

\section{Borehole Sandstone Tests}

In order to understand the influence of different borehole diameter parameters on rock mass pressure relief effect, the mechanical and acoustic emission characteristics of sandstone were studied based on laboratory tests. The stress, strain, and acoustic emission ringing of rock are monitored during the tests. To reduce the discreteness of the test, the samples are made of sandstone with good compactness and mechanical characteristics. The sandstone is gray in color and composed of quartz grains with good macroscopic homogeneity. During the preparation and processing of sandstone sample, the flatness of each section of the sample is ensured to be $0.1 \mathrm{~mm}$ through cutting, grinding, and other processes, and the adjacent surfaces of the sample are kept vertical as far as possible. The final processed samples are processed as shown in Figure 1. The sample sizes are all $50 \times 50 \times 100 \mathrm{~mm}$, and the drilling diameters $D$ are $6 \mathrm{~mm}$, $8 \mathrm{~mm}$, and $10 \mathrm{~mm}$, respectively. The processed rock samples are subjected to the uniaxial compression test on a compression testing machine, and acoustic emission probes are installed around the samples to monitor the acoustic emission characteristics during the failure process of the

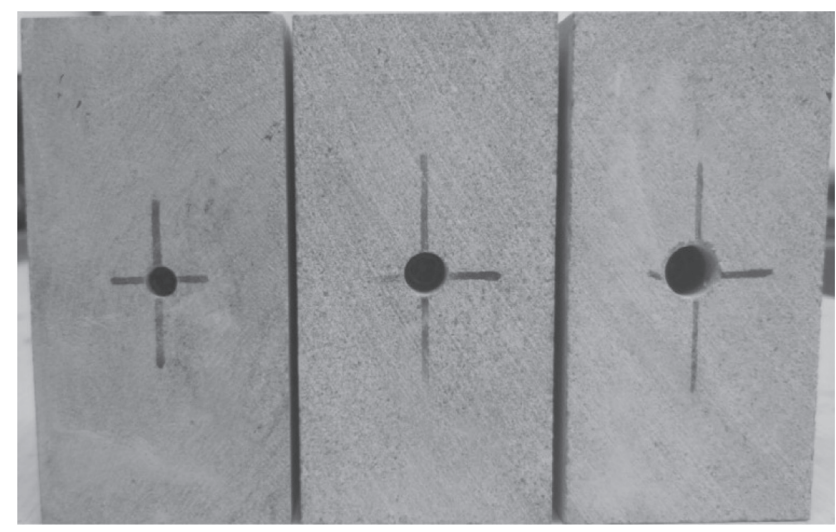

(a)

(b)

(c)

FIgURE 1: Sandstone samples with different boreholes: (a) $D=6 \mathrm{~mm}$; (b) $D=8 \mathrm{~mm}$; (c) $D=10 \mathrm{~mm}$.

samples, as shown in Figure 2. In order to make the AE monitoring more accurate, the environmental interference of $\mathrm{AE}$ was measured before the experiment, and the gain and trigger threshold of AE preamplifier were set to $40 \mathrm{~dB}$. At the same time, in order to better analyze the influence of borehole diameter on unloading failure characteristics of rock mass, a control group without borehole sample was set up, as shown in Figure 2. The loading speed of all the samples is $0.02 \mathrm{~mm} / \mathrm{s}$.

\section{Analysis of Test Results}

3.1. Mechanical Characteristics of Borehole Sandstone. The failure stress-strain curves of sandstone with different borehole diameters are obtained through mechanical tests, as shown in Figure 3. The peak stress, UCS, of sandstone with different borehole diameters is shown in Figure 4. It can be seen from Figure 3 that there are four obvious stages in the stress-strain curve. In the initial compaction stage (OA), with the increase in loading stress, the initial cracks and holes in the samples are compacted under pressure and the stress-strain curve shows a concave trend; the transverse strain is small, and the specimen volume decreases with the increase in load. In the elastic stage $(\mathrm{AB})$, with the increase in strain, the stress increases and the rate of stress increase is large, and the stress-strain curve is approximately linear. The reason is that in this stage, the crack of the sample is stable development. In the strain hardening stage (BC), with the increase in strain, the stress also increases, but the increasing rate gradually decreases, and the stress-strain curve is concave. At this stage, the crack propagates unsteadily and accumulates a lot. In the post peak failure stage (CD), with the increase in strain, the bearing capacity of rock decreases rapidly, and the crack penetrates through the samples.

It can be seen from Figure 4 that the peak strength of sandstone is $82.1 \mathrm{MPa}$, 75.3 MPa, 64.3 MPa, and $59.7 \mathrm{MPa}$ when the diameter $D$ of different holes is $0 \mathrm{~mm}$ (without drilling), $6 \mathrm{~mm}, 8 \mathrm{~mm}$, and $10 \mathrm{~mm}$, respectively. With the increase in borehole diameter, the peak strength decreases gradually, and the peak strength decreases by $8.2 \%, 21.6 \%$, 


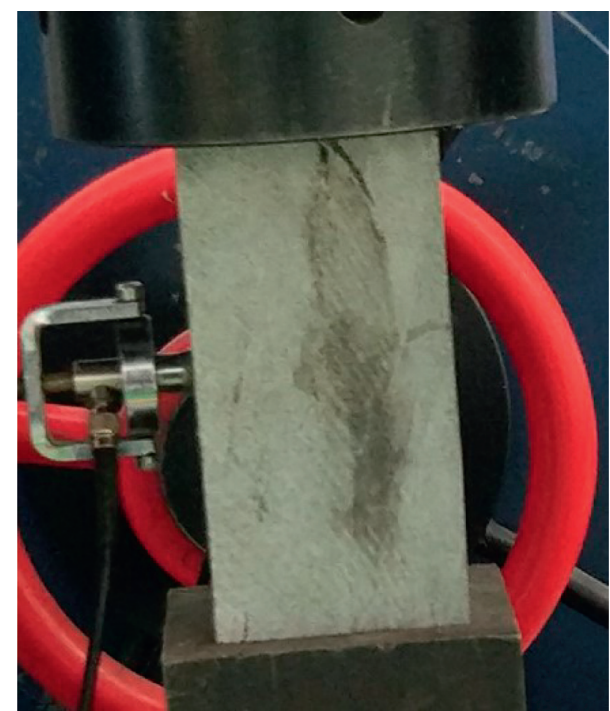

Figure 2: Sample without borehole.

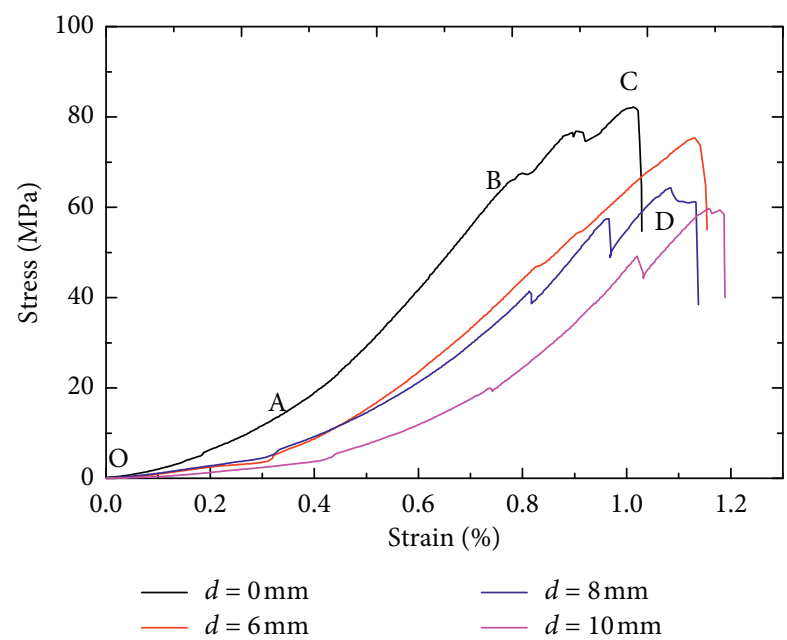

Figure 3: Stress-strain curves of rock with different borehole diameters.

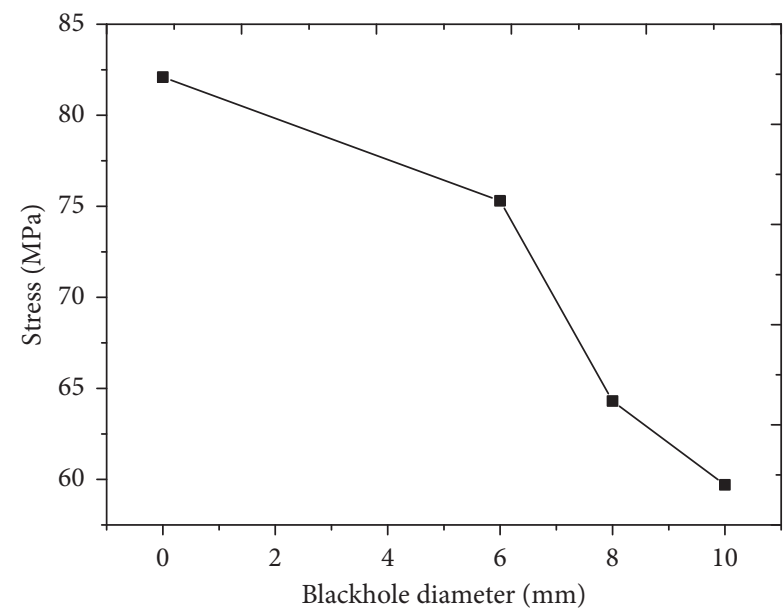

FIGURE 4: UCS of rock with different borehole diameters. and $27.3 \%$, which shows obvious pressure relief effect. It can be concluded that the pressure relief effect can be achieved by increasing the diameter of the borehole.

\subsection{Acoustic Emission Characteristics of Borehole Sandstone} Damage. The analysis of acoustic emission characteristics can reflect the accumulation and evolution process of microfracture in rock mass, and the crack growth rate of samples also reflects the pressure relief effect of rock mass. The damage and failure characteristics of drilling samples are mainly analyzed from the aspect of acoustic emission counts since it can well reflect the damage characteristics of rock mass [21]. According to the acoustic emission test result, the stress-strain-counts curve of sandstone with different borehole diameters is obtained, as shown in Figure 5. In different stages of the stress-strain curve, the emission counts of sandstone with different borehole diameters have different characteristics. In the initial compaction stage, with the increase in axial stress, the microcracks in the rock are compacted. Because the stress is relative small, the acoustic emission counts generated in this process are weak, and only a small number of acoustic emission events occur. In the elastic-plastic stage, due to the continuous increase in stress, some damage occurs in the rock mass and some acoustic emission counts are generated. Obvious acoustic emission events can be seen. At this time, the cumulative number of acoustic emission counts increases slowly. In the strain hardening stage, the acoustic emission counts rate is active, and there is a sudden increase in the acoustic emission counts at the place where the stress curve fluctuates greatly, which indicates that the crack propagation of the sample is rapid and the number of cracks increases rapidly, releasing a lot of elastic energy. Moreover, the acoustic emission count is the largest near the peak stress, and the acoustic emission counts are the strongest. In the post peak failure stage, the samples lose their load-bearing capacity and almost no crack occurs. The acoustic emission ringing count decreases rapidly and finally tends to zero. It can be seen that the acoustic emission phenomenon can better reflect the internal damage of rock mass and help to explain the pressure relief effect of rock mass with different borehole diameters.

From Figure 5, it is also obtained that different borehole diameters do not change the overall trend of acoustic emission evolution, but it will lead to different acoustic emission count characteristics of rock damage and failure, especially the maximum acoustic emission count characteristics and corresponding strain values. The maximum value of $\mathrm{AE}$ is about 2600, and the corresponding strain value is about $1.02 \%$; for the sample with a diameter of $6 \mathrm{~mm}$, the maximum value of $\mathrm{AE}$ is about 1750 and the corresponding strain value is about $1.15 \%$; for the sample with a diameter of $8 \mathrm{~mm}$, the maximum value of $\mathrm{AE}$ is about 7000 and the corresponding strain value is about $1.08 \%$; for the sample with a diameter of $6 \mathrm{~mm}$, the maximum value of $\mathrm{AE}$ is about 8700 and the corresponding strain value is about $1.08 \%$. Through comparison, it is found that the occurrence of borehole will lead to the increase in the maximum count value and the corresponding strain value of acoustic 


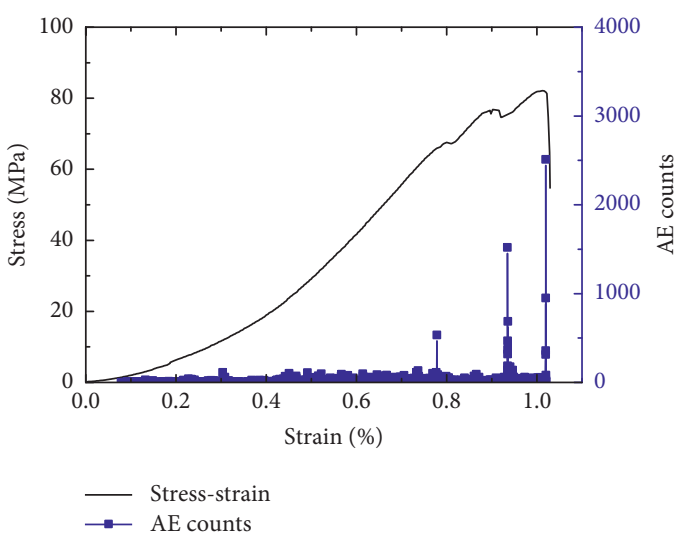

(a)

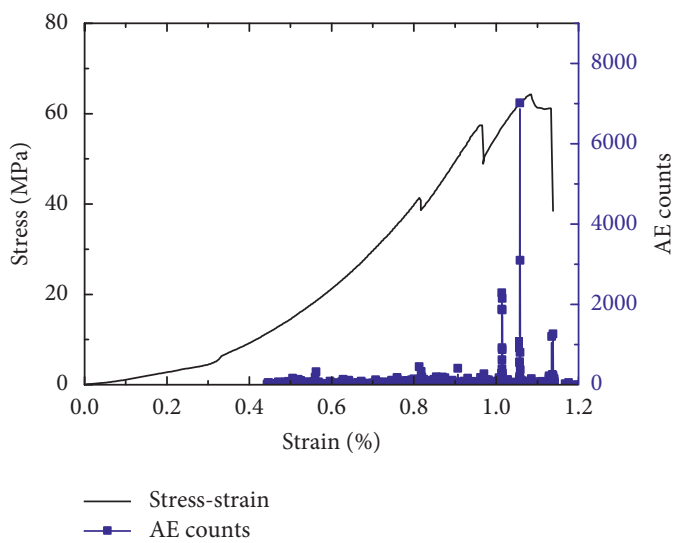

(c)

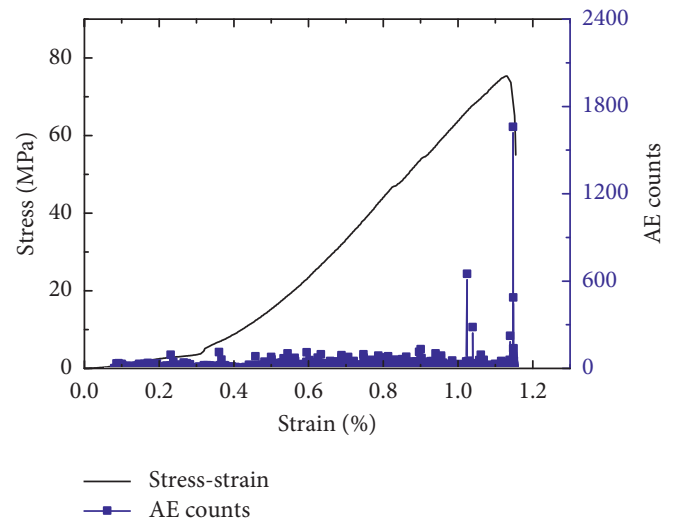

(b)

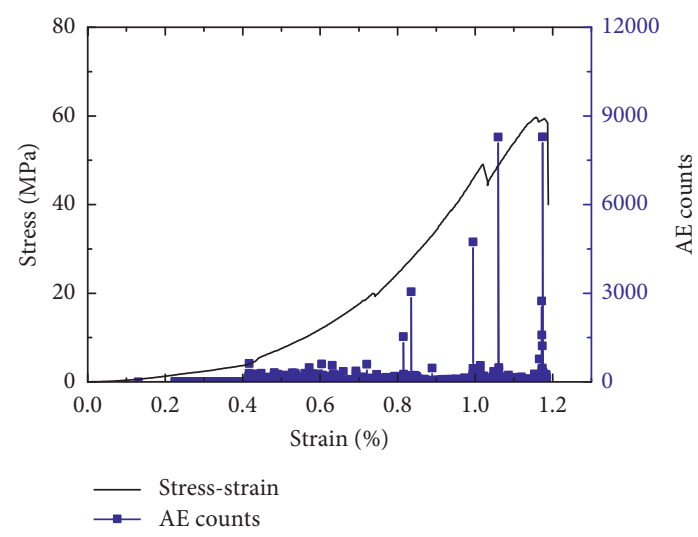

(d)

FiguRE 5: Stress-strain-acoustic emission counts curves with different borehole diameters: (a) $D=0 \mathrm{~mm}$; (b) $D=6 \mathrm{~mm}$; (c) $D=8 \mathrm{~mm}$; (d) $D=10 \mathrm{~mm}$.

emission. Using this feature, rock burst disasters can be predicted better.

\subsection{Failure Morphology Characteristics of Borehole Sandstone.} Figure 6 shows failure modes of samples with different borehole diameters. It can be seen from these figures that when the borehole diameter is $0 \mathrm{~mm}$, the failure of the sample is inclined splitting failure and the failure modes is "/". However, the failure modes of rock mass are changed as the borehole diameters. When the borehole diameter is $6 \mathrm{~mm}$, the crack extends upward and downward from the top of the hole, and there is approximately vertical through failure. The overall failure of the sample is a main control crack, mainly tensile failure, and the failure modes are similar to "|". When the hole diameter is $8 \mathrm{~mm}$, the crack mainly occurs in the upper right corner and the lower left corner. In addition to the main control crack, there are microcracks around the hole and the failure modes are similar to " $Y$." When the diameter of the hole is $10 \mathrm{~mm}$, three dominant cracks are formed in the upper and lower right directions of the hole, accompanied by small cracks, and the failure modes are similar to " $y$." When there is no hole, the crack mainly propagates from the top to the bottom. When there is a hole, the crack first occurs around the hole and then extends along the hole to both sides of the sample. It can be seen that crack propagation and penetration are the fundamental reason for drilling pressure relief.

\section{Numerical Simulation of Sandstone Failure with Different Borehole Diameters}

4.1. Selection of Numerical Model. Sandstone is the sedimentary rock formed by the cementation of lithic particles, and the sandstone particles and cementation can be clearly seen under magnification, as shown in Figure 7 [22]. The debris particles are hard and strong and are not easy to be broken. The failure of sandstone is mainly due to the cementation fracture between fine particles, which forms cracks. The crack propagation and penetration eventually form the macrofailure of the sample. Therefore, rock mass materials can be simulated by means of particle flow code (PFC). PFC program is based on discrete element framework to simulate finite size and number of particles, as well as the movement and interaction between particles [23, 24]. There are mainly contact bond model and parallel bond model to describe the contact between particles. The latter can simulate the compression failure of rock like materials along the normal or tangential direction, which can better reflect the 


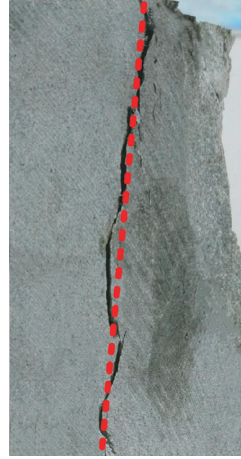

(a)

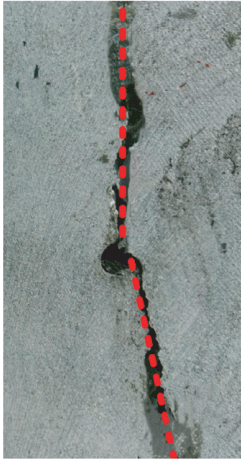

(b)

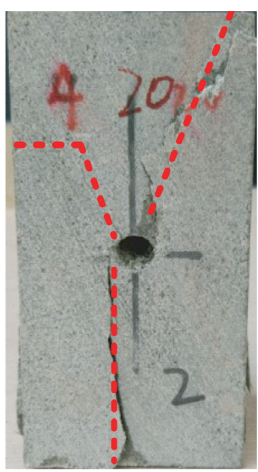

(c)

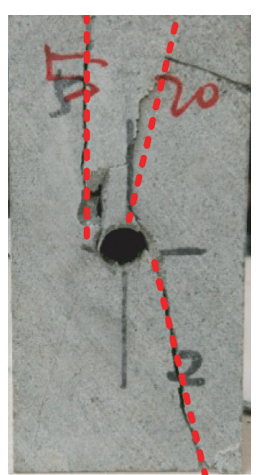

(d)

FIGURE 6: Failure morphology of samples with different borehole diameters: (a) $D=0 \mathrm{~mm}$; (b) $D=6 \mathrm{~mm}$; (c) $D=8 \mathrm{~mm}$; (d) $D=10 \mathrm{~mm}$.

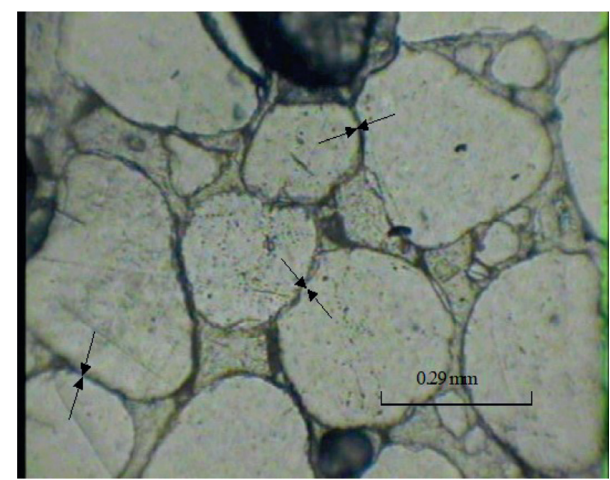

FIGURE 7: Grain cement structure of sandstone [22].

failure mode of rock like materials. Therefore, the parallel bond model is selected in this paper.

4.2. Model Parameter Checking. In the parallel bond model of PFC, the macromechanical behavior of rock is mainly determined by the microparameters such as effective modulus of particles, particle stiffness ratio, effective modulus of parallel bond, stiffness ratio of parallel bond, parallel bond tensile strength, parallel bond cohesive force, and friction coefficient [23-25]. Usually, the microparameters of PFC rock models are calibrated by the "trial-and-error" method $[23,24]$. The elastic modulus and compressive strength of the intact rock samples are about $14.6 \mathrm{GPa}$ and $82 \mathrm{MPa}$. Therefore, the numerical model is mainly checked by these two parameters. Firstly, the numerical model as shown in Figure $7(\mathrm{a})$ is established. The radius of particles is $0.3-0.5 \mathrm{~mm}$, and 8753 balls are generated. Then, the model is given the above parameters, and the model is uniaxial compressed, and the loading speed is $0.01 \mathrm{~m} / \mathrm{s}$ by moving the wall in top. Through repeated trial and error, the parameters in Table 1 can simulate the sandstone well, as shown in Figures 8 and 9 . The elastic modulus and uniaxial compressive strength of the numerical sandstone are 13.34 $\mathrm{GPa}$ and $83.8 \mathrm{MPa}$, and the deviations with the real sandstone are $0.39 \mathrm{GPa}$ and $1.3 \mathrm{MPa}$.
TABle 1: Physico-mechanical parameters of the numerical sandstone model.

\begin{tabular}{lc}
\hline Parameter & Value \\
\hline Minimum diameter $(\mathrm{mm})$ & 0.6 \\
Maximum diameter $(\mathrm{mm})$ & 1.0 \\
Effective modulus of particles $(\mathrm{GPa})$ & 12 \\
Effective modulus of parallel bond $(\mathrm{GPa})$ & 15 \\
Stiffness ratio of parallel bond & 2.0 \\
Friction coefficient & 0.6 \\
Density $\left(\mathrm{kg} / \mathrm{m}^{3}\right)$ & 2500 \\
Parallel bond tensile strength $(\mathrm{MPa})$ & 24 \\
Parallel bond cohesive force $(\mathrm{MPa})$ & 51 \\
Particle stiffness ratio & 2.0 \\
\hline
\end{tabular}

4.3. Analysis Model and Results. In order to further analyze the influence of borehole pressure relief on rock damage and failure, the evolution process of instability and failure of samples with different borehole diameters is simulated. The analysis contents are as follows: through the preparation of FISH language, the failure mode of rock sample in UCS and the failure mode of $10 \%$ UCS, $30 \%$ UCS, $50 \%$ UCS, $70 \%$ UCS, and $90 \%$ UCS before the peak and 10\% UCS and 30\% UCS after the peak stress are monitored, as shown in Figure 10. The " + " represents that the monitoring points are before peak stress, and the "-" represents that the monitoring points are after peak stress.

Figures 11-14 show the failure evolution of numerical samples of rocks with different borehole diameters. It can be seen from the figures that for the rock sample without borehole, when the stress is less than 70\% of the UCS (before peak stress), the internal failure is small. When the compressive stress reaches $90 \%$ of the peak stress, the crack inside the sample develops rapidly, which is consistent with the results of the acoustic emission counting. This means that the failure of the samples is mainly in the peak stage. After the compression stress exceeded the UCS, the damage of the sample was more serious, and the cracks are mainly concentrated in the inclined angle of 60 degrees. The failure form of the complete rock sample is mainly inclined splitting failure. The failure shape is " $/$ ", which is consistent with the failure mode of the laboratory test. For the rock samples with 


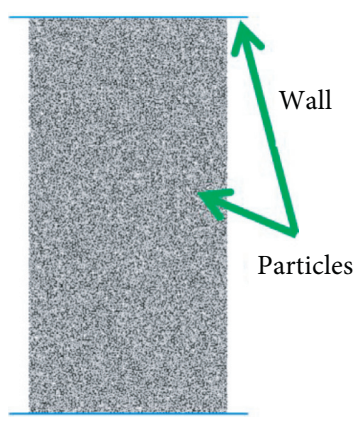

(a)

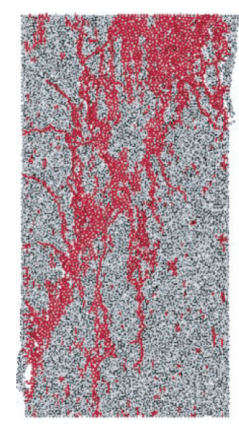

(b)

FIgure 8: Numerical model and failure mode: (a) initial model; (b) failure model.

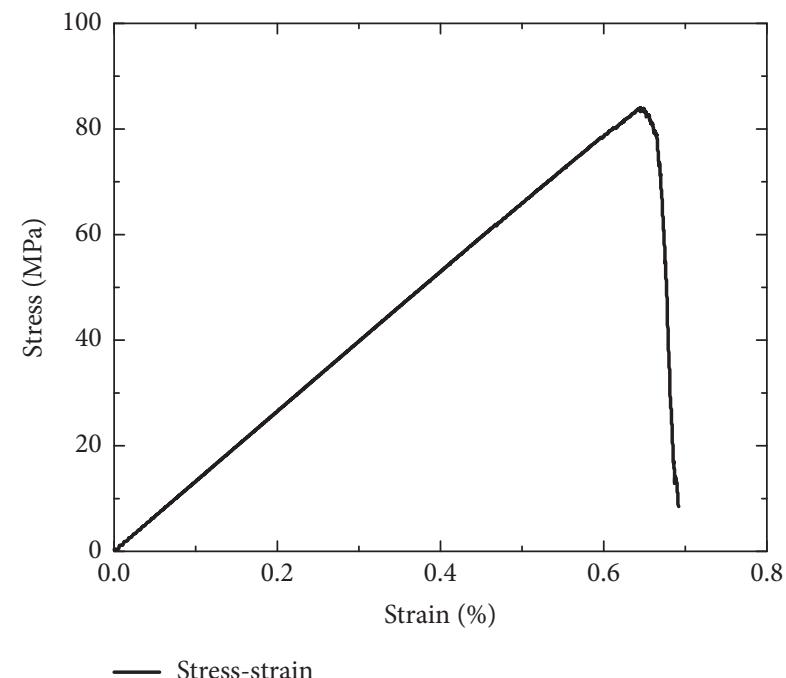

FIGURE 9: Stress-strain curve of the numerical sandstone intact model.

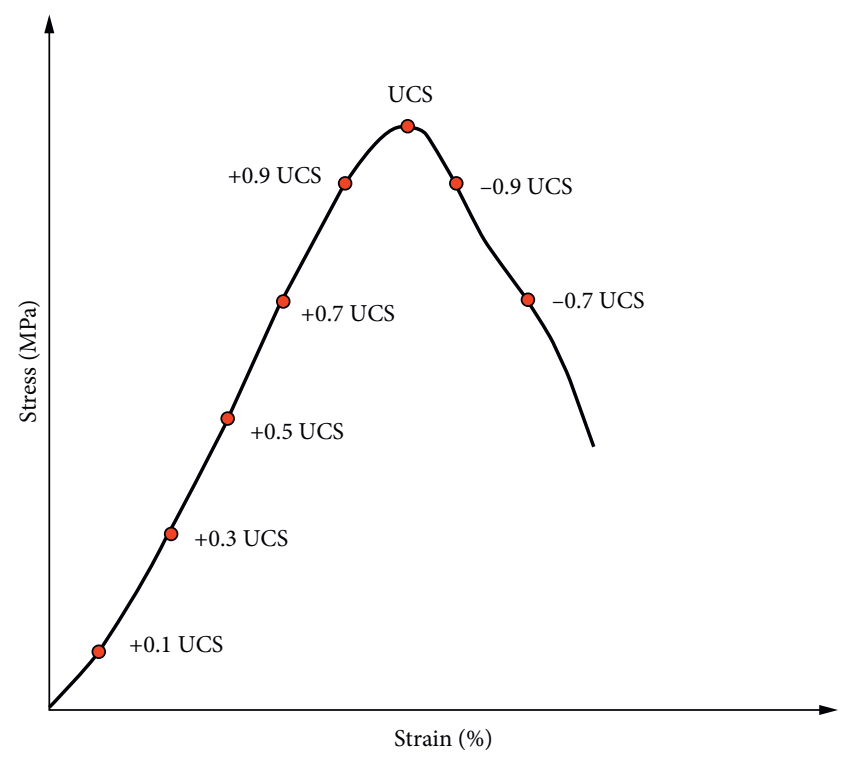

Figure 10: Schematic diagram of failure mode analysis and monitoring: (a) +0.1UCS; (b) +0.3UCS; (c) +0.5UCS; (d) +0.7UCS; (e) +0.9UCS; (f) UCS; (g) -0.9UCS; (h) -0.7UCS. boreholes, when the stress is less than $50 \%$ of the prepeak stress, the sample is basically nondestructive. However, when the stress reaches $70 \%$ of the peak stress, cracks are generated in the inner part of the sample, i.e., near the borehole, and the cracks are perpendicular to the development of the cavern. This mechanism will be analyzed in section 4.4. The crack propagates along the upper left corner and the lower right corner of the specimen, forming different failure modes. The failure mode is similar to inverted $y$ shape. For the complete specimen, the cracks are distributed in the whole specimen when the stress is small. With the increase in the stress, the cracks begin to expand in a certain direction and form a certain shape of failure zone. For the sample with drilling hole, the crack first appears around the drilling hole. With the further increase in stress, the cracks around the borehole increase and expand outward gradually and the crack propagates along the hole with the cracks formed in other places to form a failure zone. With the further increase in stress, the cracks around the borehole increase and expand outward gradually. The failure evolution characteristics of rock samples with different drilling diameter conditions show that with the increase in drilling hole diameters, the higher the damage degree of rock mass is, the faster the crack propagation speed is, which is also the reason why the increase in borehole diameter leads to the larger unloading range.

4.4. Theoretical Analysis of Rock Failure with Borehole. For the rock mass drilled, the mechanism of crack formation can be analyzed from the stress concentration of the borehole. The analytical expression of stress of the hole when the model subjected to compressive stress $\sigma_{1}$ is as follows [26]:

$$
\begin{aligned}
& \sigma_{r}=\frac{\sigma_{1}}{2}\left(1-\frac{r_{1}^{2}}{r^{2}}\right)-\frac{\sigma_{1}}{2}\left(1-4\left(\frac{r_{1}^{2}}{r^{2}}+3 \frac{r_{1}^{4}}{r^{4}}\right)\right) \cos 2 \theta, \\
& \sigma_{\theta}=\frac{\sigma_{1}}{2}\left(1+\frac{r_{1}^{2}}{r^{2}}\right)+\frac{\sigma_{1}}{2}\left((1+3) \frac{r_{1}^{4}}{r^{4}}\right) \cos 2 \theta,
\end{aligned}
$$

where $\sigma_{r}$ is the radial stress of surrounding rock, $\sigma_{\theta}$ is the tangential stress of surrounding rock, $\sigma_{1}$ is the compressive stress, and $r_{1}$ is the radius of the hole. 


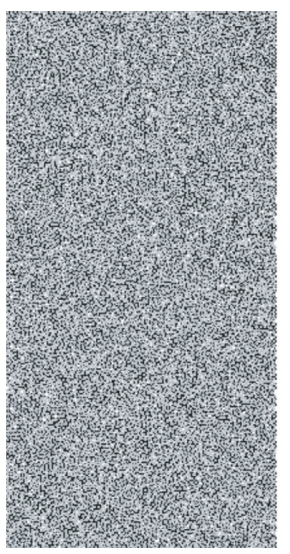

(a)

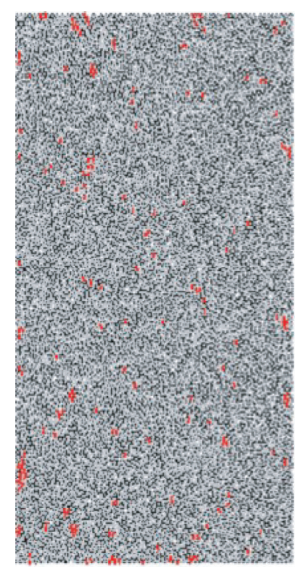

(e)

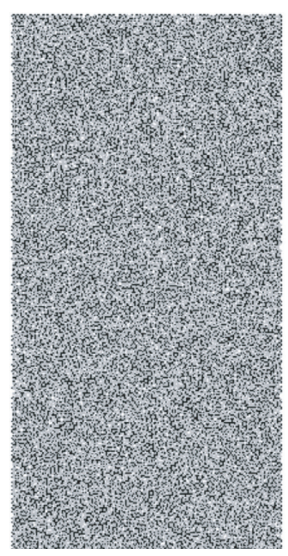

(b)

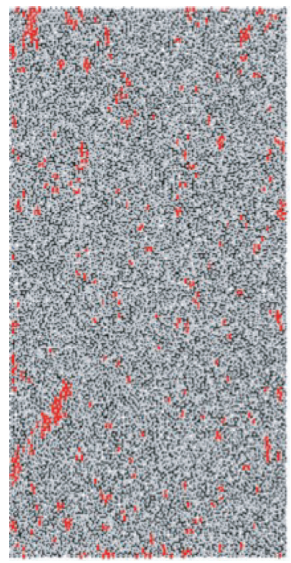

(f)

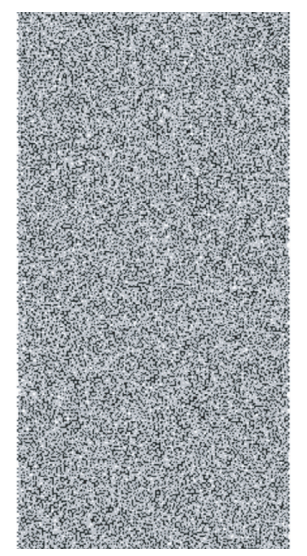

(c)

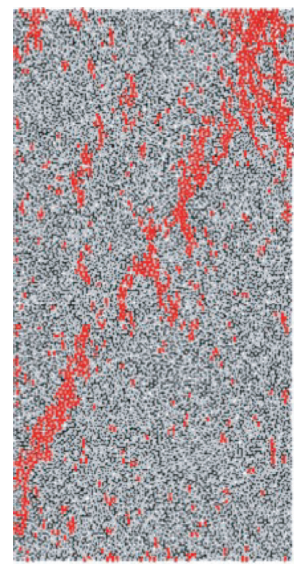

(g)

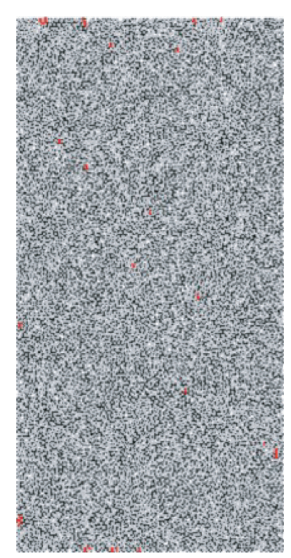

(d)

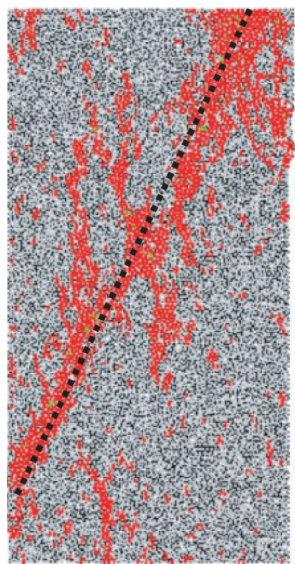

(h)

FIGURE 11: Damage evolution modes of rock mass without borehole: (a) +0.1UCS; (b) +0.3UCS; (c) +0.5UCS; (d) +0.7UCS; (e) +0.9UCS; (f) UCS; (g) -0.9UCS; (h) -0.7UCS.

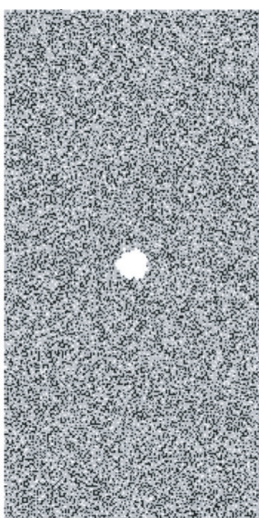

(a)

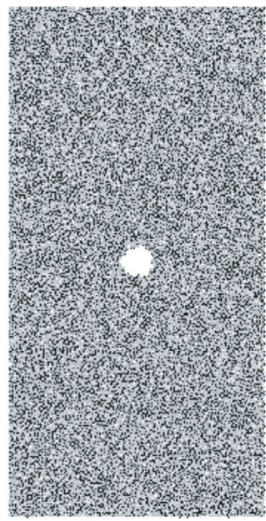

(b)

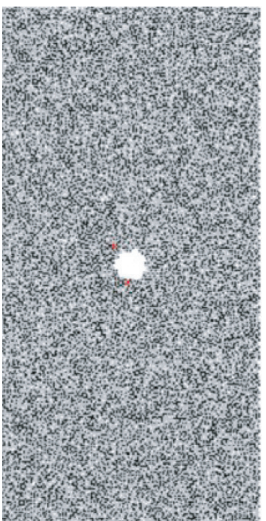

(c)

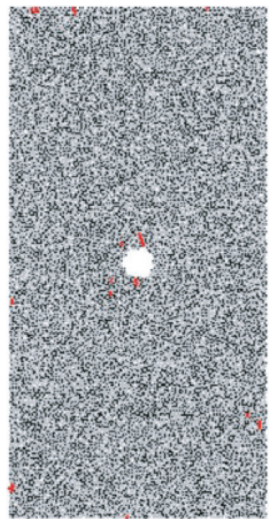

(d)

FIgURE 12: Continued. 


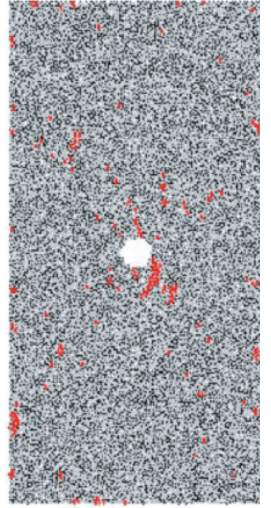

(e)

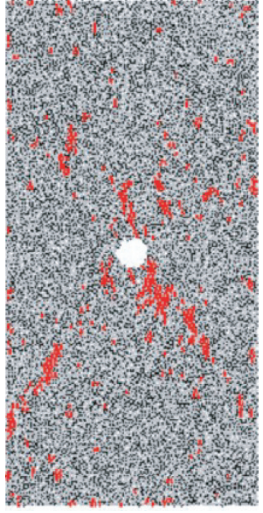

(f)

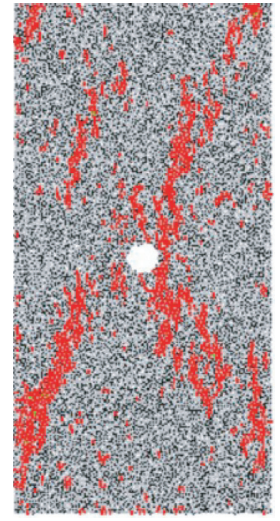

(g)

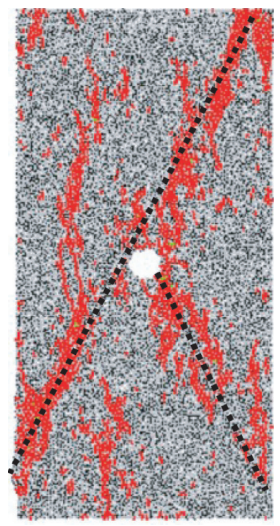

(h)

FIGURE 12: Damage evolution modes of rock mass with borehole diameter as $6 \mathrm{~mm}$ : (a) $+0.1 \mathrm{UCS}$; (b) $+0.3 \mathrm{UCS}$; (c) +0.5UCS; (d) +0.7UCS; (e) +0.9UCS; (f) UCS; (g) -0.9UCS; (h) -0.7UCS.

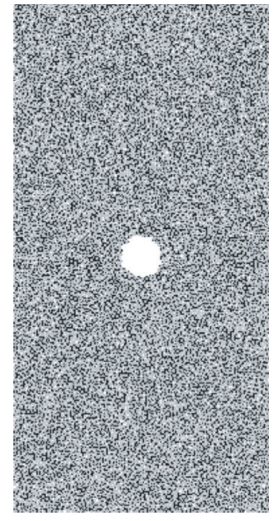

(a)

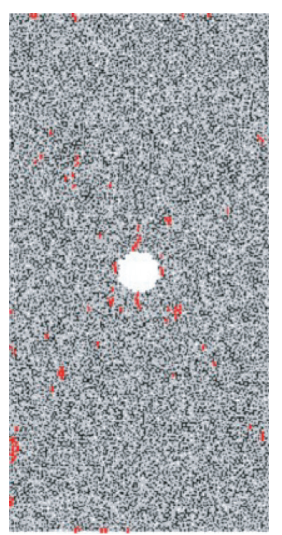

(e)

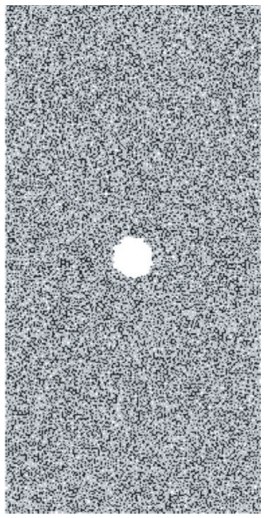

(b)

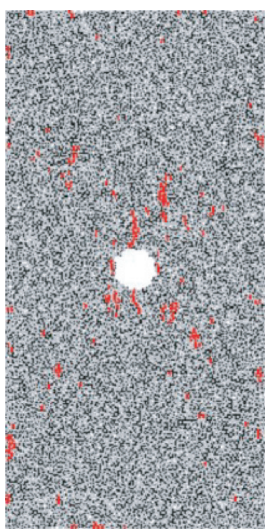

(f)

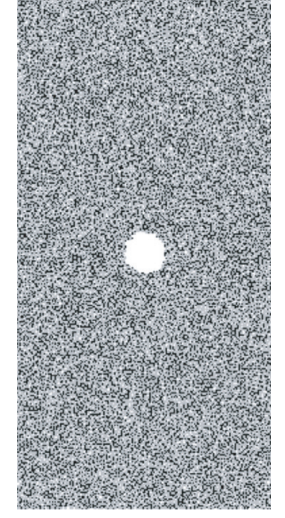

(c)

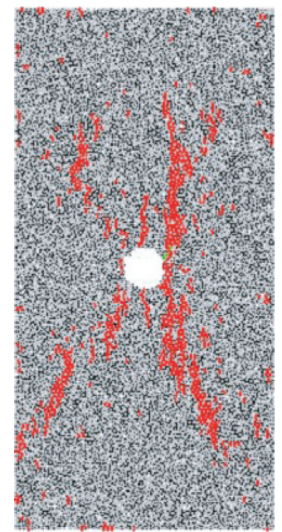

(g)

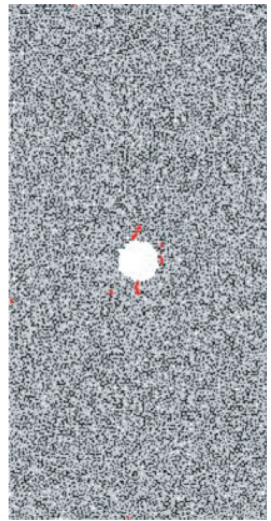

(d)

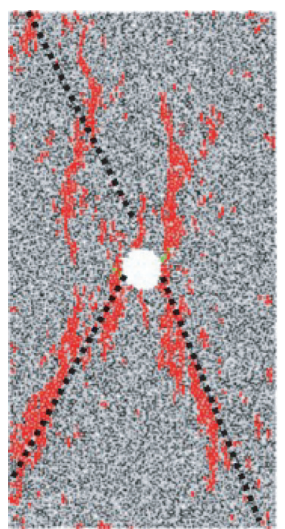

(h)

FIGURE 13: Damage evolution modes of rock mass with borehole diameter as $8 \mathrm{~mm}$ : (a) $+0.1 \mathrm{UCS}$; (b) $+0.3 \mathrm{UCS}$; (c) $+0.5 \mathrm{UCS}$; (d) +0.7UCS; (e) +0.9UCS; (f) UCS; (g) -0.9UCS; (h) -0.7UCS.

Through formula (1), when $r=r_{1}$, the stress distribution expression around the hole is calculated as follows:

$$
\begin{aligned}
& \sigma_{r}=0, \\
& \sigma_{\theta}=\sigma_{1}+2 \sigma_{1} \cos 2 \theta .
\end{aligned}
$$

From formula (2), it can be obtained that when $\theta=0^{\circ}$, the tangential stress $\sigma_{\theta}=3 \sigma_{1}$, and when $\theta=90^{\circ}$, the tangential stress $\sigma_{\theta}=-\sigma_{1}$. This shows that the compressive stress concentration occurs on the left and right sides of the circular hole, and the tensile stress concentration occurs at the top and bottom boundary of the hole. It also means that the top rock will break first due to tensile stress. As shown in Figures 11-14, the failure of drilling rock mass begins with borehole failure, and the main failure is tensile failure at the top and bottom. This shows that drilling is 


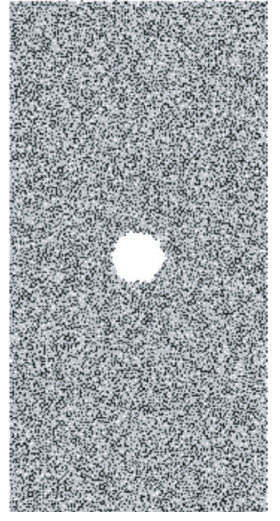

(a)

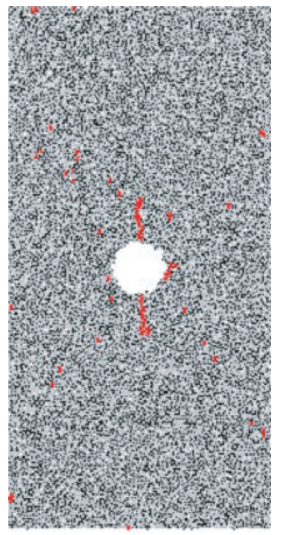

(e)

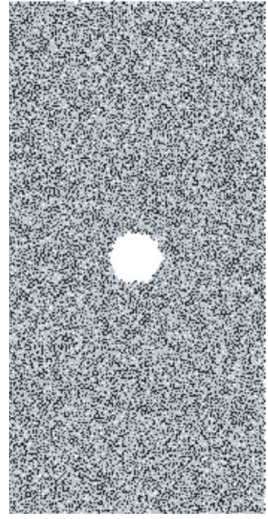

(b)

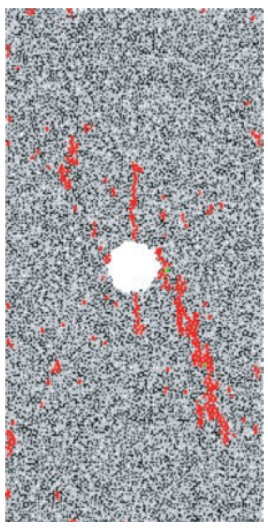

(f)

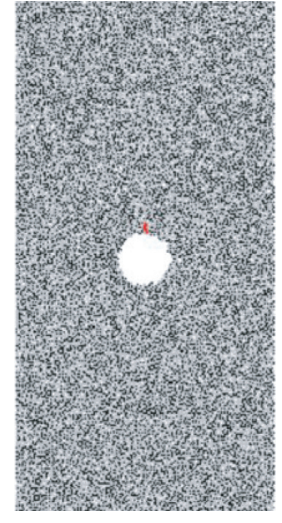

(c)

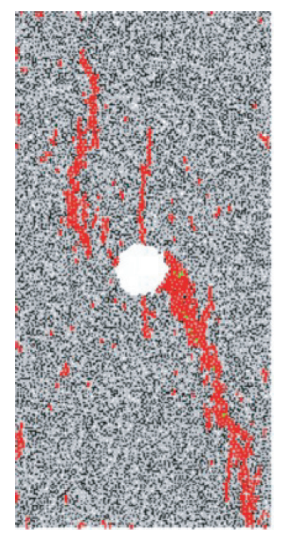

(g)

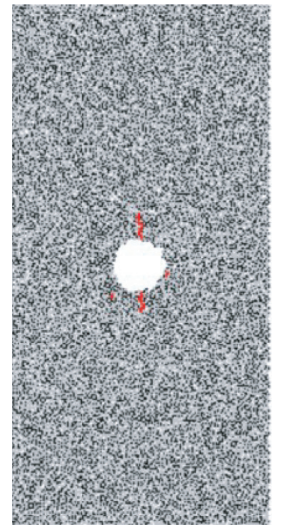

(d)

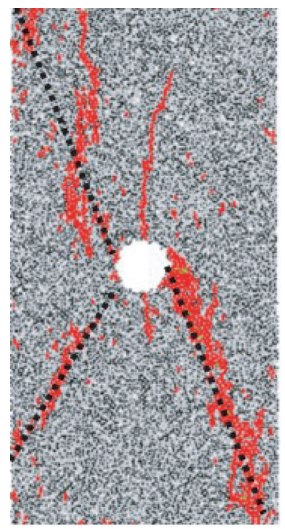

(h)

FIgURE 14: Damage evolution modes of rock mass with borehole diameter as $10 \mathrm{~mm}$.

beneficial to deformation and crack propagation of rock mass and helps to reduce high stress and energy in rock mass.

\section{Conclusions}

Based on laboratory experiments and numerical simulation, this paper analyzed pressure relief effect and rock failure characteristics with different borehole diameters and obtained the following conclusions.

With the increase in borehole diameter, the effect of borehole pressure relief is better. The peak strength decreases by $8.2 \%, 21.6 \%$, and $27.3 \%$ when borehole diameter increases from $0 \mathrm{~mm}$ to $10 \mathrm{~mm}$. The pressure relief effect can be achieved by increasing the diameter of the borehole.

Acoustic emission can effectively reflect the internal damage characteristics of rock mass. With the change of stress and strain, the emission count characteristics of rock mass also show the characteristics of slow and sharp increase attenuation, and different drilling characteristics do not affect this law. However, the increase in borehole will lead to the increase in the maximum count value and the corresponding strain value of acoustic emission. Using this feature, rock burst disasters can be predicted better and potential disaster such as tunnel collapse and subsidence of strata can be prevented effectively.
The existence of drilling will lead to the failure stress of rock in advance. For the nondrilling samples, the failure starts at $70 \%$ of the stress before the peak value, while for the rock samples with different boreholes, the failure is about $50 \%$ of the stress before the peak value. Moreover, the existence of drilling causes a great change in the failure mode of the specimen. The failure of the nondrilling rock starts from the end of the rock sample, while the failure of the rock in the borehole starts from the bottom of the cavern top.

The failure evolution characteristics of rock samples are different under different borehole diameters. With the increase in borehole diameter, the more serious the failure and deformation of rock mass around the borehole and the faster the crack propagation.

\section{Data Availability}

The data used to support the findings of this study are available from the corresponding author upon request.

\section{Conflicts of Interest}

The authors declare that they have no conflicts of interest to report regarding the present study. 


\section{Acknowledgments}

The research was funded by Special Scientific Research Plan of Shaanxi Provincial Department of Education (No. 18JK1046).

\section{References}

[1] C. Zhu, M.-C. He, M. Karakus, X.-H. Zhang, and Z. Guo, "The collision experiment between rolling stones of different shapes and protective cushion in open-pit mines," Journal of Mountain Science, vol. 18, no. 5, pp. 1391-1403, 2021.

[2] Q. Wang, Y. Wang, M. C. He et al., "Experimental research and application of automatically formed roadway without advance tunneling," Tunnelling and Underground Space Technology, vol. 114, no. 3, Article ID 103999, 2021.

[3] C. Zhu, M. He, M. Karakus, X. Zhang, and Z. Tao, "Numerical simulations of the failure process of anaclinal slope physical model and control mechanism of negative Poisson's ratio cable," Bulletin of Engineering Geology and the Environment, vol. 80, no. 4, pp. 3365-3380, 2021.

[4] X. Wang and F.-B. Meng, "Statistical analysis of large accidents in China's coal mines in 2016," Natural Hazards, vol. 92, no. 1, pp. 311-325, 2018.

[5] P. Konicek, K. Soucek, L. Stas, and R. Singh, "Long-hole destress blasting for rockburst control during deep underground coal mining," International Journal of Rock Mechanics and Mining Sciences, vol. 61, pp. 141-153, 2013.

[6] J. H. Liu, F. X. Jiang, G. J. Sun, Z. G. Zhang, and W. F. Tan, "Mechanism of intensive venting pulverized coal to prevent coal burst and its application," Chinese Journal of Rock Mechanics and Engineering, vol. 33, no. 4, pp. 747-754, 2014.

[7] D. Krajcinovic and M. A. G. Silva, "Statistical aspects of the continuous damage theory," International Journal of Solids and Structures, vol. 18, no. 7, pp. 551-562, 1982.

[8] C. Zhai, J. Xu, S. Liu, and L. Qin, "Investigation of the discharge law for drill cuttings used for coal outburst prediction based on different borehole diameters under various side stresses," Powder Technology, vol. 325, pp. 396-404, 2018.

[9] Q. X. Meng, W. Y. Xu, H. L. Wang, X. Y. Zhuang, W. C. Xie, and T. Rabczuk, "DigiSim- "an open source software package for heterogeneous material modeling based on digital image processing"," Advances in Engineering Software, vol. 148, Article ID 102836, 2020.

[10] Q. Wang, Z. Jiang, B. Jiang, H. Gao, Y. Huang, and P. Zhang, "Research on an automatic roadway formation method in deep mining areas by roof cutting with high-strength boltgrouting," International Journal of Rock Mechanics and Mining Sciences, vol. 128, Article ID 104264, 2020.

[11] C. Y. Jia, Y. J. Jiang, X. P. Zhang, D. Wang, H. Luan, and C.-S. Wang, "Laboratory and numerical experiments on pressure relief mechanism of large-diameter boreholes," Chinese Journal of Geotechnical Engineering, vol. 39, no. 6, pp. 1115-1122, 2017.

[12] E. B. Yi, Z. L. Mu, L. M. Dou, J. G. Ju, and L. Xie, "Study on comparison and analysis on pressure releasing effect of boreholes in soft and hard seam," Coal Science and Technology, vol. 39, no. 6, pp. 1-5, 2011.

[13] Y. Wang, W. K. Feng, R. L. Hu, and C. H. Li, "Fracture evolution and energy characteristics during marble failure under triaxial fatigue cyclic and confining pressure unloading (FC-CPU) conditions," Rock Mechanics and Rock Engineering, vol. 54, no. 2, pp. 799-818, 2021.
[14] B. W. Ma, Z. G. Deng, S. K. Zhao, and S. G. Li, "Analysis on the mechanism and influencing factors of drilling pressure relief to prevent rock burst," Coal Science and Technology, vol. 48, no. 5, pp. 35-40, 2020.

[15] D. Gai, D. Li, and F. Jiang, "Reasonable pressure-relief borehole spacing in coal of different strength," Journal of Mining \& Safety Engineering, vol. 37, no. 3, pp. 578-585, 2020.

[16] Y. Li, H. Zhang, and Z. Zhu, C. Guo, Study on safety parameters of pressure relief borehole in rockburst coal seam," China Safety Science Journal, vol. 28, no. 11, pp. 122-128, 2018.

[17] X.-D. Zhao, H.-X. Zhang, and W.-C. Zhu, "Fracture evolution around pre-existing cylindrical cavities in brittle rocks under uniaxial compression," Transactions of Nonferrous Metals Society of China, vol. 24, no. 3, pp. 806-815, 2014.

[18] J. Xu, G. Dai, W. Gong, Q. Zhang, A. Haque, and R. P. Gamage, "A review of research on the shaft resistance of rock-socketed piles," Acta Geotechnica, vol. 16, no. 3, pp. 653-677, 2021.

[19] H. Wu, G. Zhao, and W. Liang, "Mechanical properties and fracture characteristics of pre-holed rocks subjected to uniaxial loading: a comparative analysis of five hole shapes," Theoretical and Applied Fracture Mechanics, vol. 105, Article ID 102433, 2020.

[20] P. Lin, R. H. C. Wong, and C. A. Tang, "Experimental study of coalescence mechanisms and failure under uniaxial compression of granite containing multiple holes," International Journal of Rock Mechanics and Mining Sciences, vol. 77, pp. 313-327, 2015.

[21] X. Wang, Z. Wen, Y. Jiang, and H. Huang, "Experimental study on mechanical and acoustic emission characteristics of rock-like material under non-uniformly distributed loads," Rock Mechanics and Rock Engineering, vol. 51, no. 3, pp. 729-745, 2018.

[22] M. Dittes and J. F. Labuz, "Field and laboratory testing of st. Peter sandstone," Journal of Geotechnical and Geoenvironmental Engineering, vol. 128, no. 5, pp. 372-380, 2002.

[23] U. Castro-Filgueira, L. R. Alejano, J. Arzúab, and D. M. Ivars, "Sensitivity analysis of the micro-parameters used in a PFC analysis towards the mechanical properties of rocks," Procedia Engineering, vol. 191, pp. 488-495, 2017.

[24] X. P. Zhang and L. N. Y. Wong, "Cracking processes in rocklike material containing a single flaw under uniaxial compression: a numerical study based on parallel bonded-particle model approach," Rock Mechanics and Rock Engineering, vol. 45, no. 5, pp. 711-737, 2012.

[25] Itasca Consulting Group, PFC Users' Manual (Version 5.0), Minnestota: Inc, Minneapolis, Minnestoa, 2014.

[26] L. Cui, J.-J. Zheng, R.-J. Zhang, and Y.-K. Dong, "Elastoplastic analysis of a circular opening in rock mass with confining stress-dependent strain-softening behaviour," Tunnelling and Underground Space Technology, vol. 50, pp. 94-108, 2015. 